\section{(2) OPEN ACCESS}

\title{
Quality indicators for the primary care of osteoarthritis: a systematic review
}

\author{
J J Edwards, ${ }^{1}$ M Khanna, ${ }^{2}$ K P Jordan, ${ }^{1}$ J L Jordan, ${ }^{1}$ J Bedson, ${ }^{1}$ K S Dziedzic ${ }^{1}$
}

\begin{abstract}
Handling editor Tore K Kvien
- Additional material is published online only. To view please visit the journal online (http://dx.doi.org/10.1136/ annrheumdis-2013-203913).

${ }^{1}$ Arthritis Research UK Primary Care Centre, Research Institute for Primary Care \& Health Sciences, Keele University, Keele, Staffordshire, UK EEarnswood Medical Centre, Eagle Bridge Health \& Well Being Centre, Crewe, Cheshire, UK
\end{abstract}

\section{Correspondence to} Dr J J Edwards, Arthritis Research UK Primary Care Centre, Research Institute for Primary Care \& Health Sciences, Keele University, Keele, Staffordshire ST5 5BG, UK; j.j.edwards@keele.ac.uk

Received 8 May 2013 Revised 9 September 2013 Accepted 6 November 2013 Published Online First 28 November 2013

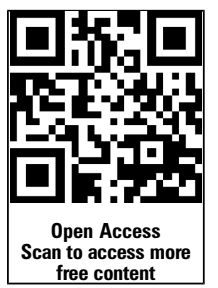

\section{ABSTRACT}

Objective To identify valid and feasible quality indicators for the primary care of osteoarthritis (OA).

Design Systematic review and narrative synthesis. Data sources Electronic reference databases (MEDLINE, EMBASE, CINAHL, HMIC, PsychINFO), quality indicator repositories, subject experts.

Eligibility criteria Eligible articles referred to adults with $\mathrm{OA}$, focused on development or implementation of quality indicators, and relevant to UK primary care. An English language restriction was used. The date range for the search was January 2000 to August 2013. The majority of OA management guidance has been published within this time frame.

Data extraction Relevant studies were quality assessed using previous quality indicator methodology. Two reviewers independently extracted data. Articles were assessed through the Outcome Measures in Rheumatology filter; indicators were mapped to management guidance for $\mathrm{OA}$ in adults. A narrative synthesis was used to combine the indicators within themes.

Results 10853 articles were identified from the search; 32 were included in the review. Fifteen indicators were considered valid and feasible for implementation in primary care; these related to assessment nonpharmacological and pharmacological management. Another 10 indicators were considered less feasible, in various aspects of assessment and management. A small number of recommendations had no published corresponding quality indicator, such as use of topical non-steroidal anti-inflammatory drugs. No negative ('do not $\mathrm{do}^{\prime}$ ) indicators were identified.

Conclusions and implications of key findings There are well-developed, feasible indicators of quality of care for OA which could be implemented in primary care. Their use would assist the audit and quality improvement for this common and frequently disabling condition.

\section{BACKGROUND}

Osteoarthritis (OA) is a common reason for consultation with a general practitioner (GP): around $4 \%$ of the population aged 45 years and over will consult a GP in a year with a diagnosis of OA. ${ }^{1}$ One working definition of OA is "persistent joint pain that is worse with use [in people] age 45 years old and over [who have] morning stiffness lasting no more than half an hour" and does not require radiography for diagnosis. ${ }^{2}$ There are evidencebased interventions to reduce pain and disability in adults with OA. Guidance on the care and management of OA has been produced by the American
College of Rheumatology, the European League Against Rheumatism, the Osteoarthritis Research Society International, and the National Institute for Health and Care Excellence (NICE). ${ }^{3-8}$ Although management may vary by the site of $\mathrm{OA}$, core aspects of primary care management are generally common across all sites. ${ }^{4-68}$ If these interventions were routinely implemented by GPs, there would be a significant impact on population levels of pain and disability attributable to OA. ${ }^{9}$ However, there is evidence that such implementation is not occurring. ${ }^{10-15}$

Routine audit and feedback on provided care is needed to improve the quality of that care. Quality indicators (hereafter 'indicators') are one suitable tool. ${ }^{16}$ Such indicators are defined as a "measurable [element] of practice performance for which there is evidence or consensus that it can be used to assess the quality, and hence change in the quality, of care provided". ${ }^{17}$ Although reviews by Hochberg ${ }^{18}$ and Strömbeck et $a l^{19}$ identified indicators for measuring quality of care for OA, which show promise for use in primary care, there has been no systematic review and synthesis of the development and implementation literature to identify the most promising and feasible set of primary care OA indicators. Hunter et $a l^{20}$ argue cogently for 'further systematic development, implementation, and audit of quality measures.' The objective of this systematic review was to identify existing indicators of core treatment for OA feasible for use in primary care medical records and for routine audit purposes through electronic data retrieval.

\section{METHODS}

We used the methodology for systematic reviews set out by the Centre for Reviews and Dissemination. ${ }^{21}$

\section{Review protocol}

Available on request from the corresponding author.

\section{Search strategy}

A search strategy was developed to identify articles concerning the development, testing or implementation of indicators of the quality of care for $\mathrm{OA}$ applicable to adults in a primary medical care setting.

The systematic search strategy was customised for use in databases searchable through the UK National Health Service (NHS) Evidence portal (CINAHL, EMBASE, HMIC, MEDLINE and PsychINFO). A range of OA terms were combined with indicator terms. An English language restriction was used. The date range for the search was 
Table 1 MEDLINE search strategy

\begin{tabular}{lll}
\hline 1 & MEDLINE & ((qualit* ADI3 (outcome* OR indicat*))).ti,ab \\
2 & MEDLINE & QUALITY OF HEALTH CARE/ \\
3 & MEDLINE & QUALITY ASSURANCE, HEALTH CARE/ \\
4 & MEDLINE & BENCHMARKING/ \\
5 & MEDLINE & CLINICAL AUDIT/ \\
6 & MEDLINE & MEDICAL AUDIT/ \\
7 & MEDLINE & FACILITY REGULATION AND CONTROL/ \\
8 & MEDLINE & GUIDELINES AS TOPIC/ \\
9 & MEDLINE & PRACTICE GUIDELINES AS TOPICI \\
10 & MEDLINE & TOTAL QUALITY MANAGEMENT/ \\
11 & MEDLINE & exp UTILIZATION REVIEW/ \\
12 & MEDLINE & exp "OUTCOME AND PROCESS ASSESSMENT (HEALTH CARE)"/ \\
13 & MEDLINE & QUALITY INDICATORS, HEALTH CARE/ \\
14 & MEDLINE & 1 OR 2 OR 3 OR 4 OR 5 OR 6 OR 7 OR 8 OR 9 OR 10 OR 11 \\
& & OR 12 OR 13 \\
15 & MEDLINE & osteoarthr ${ }^{*}$.ti,ab \\
16 & MEDLINE & exp OSTEOARTHRITIS/ \\
17 & MEDLINE & 15 OR 16 \\
18 & MEDLINE & 14 AND 17 \\
19 & MEDLINE & 18 [Limit to: Publication Year 2000-Current and English \\
& & Language] \\
\hline
\end{tabular}

January 2000 to August 2013. Further studies were identified from other known repositories including the Agency for Healthcare Research and Quality. ${ }^{22}$

The search strategy for use in MEDLINE via NHS Evidence is shown in table 1 .

\section{Selection of eligible articles}

The titles identified were entered in a bibliographical database and duplicates removed. Titles were assessed for relevance by a single reviewer (JJE). The resulting abstracts were evaluated independently by two reviewers (JJE and MK). All those considered relevant by one or both reviewers were entered into the next round. The full texts of the resulting articles were obtained. These were subject to dual independent review of their relevance (JJE plus MK or KSD) and, if there was disagreement on inclusion, by a third reviewer (KSD or MK). This process yielded a final set of articles for the data abstraction round.

\section{Method of data extraction}

Data extraction forms were designed using the assessment criteria below. The extraction forms were piloted and refined by three reviewers. Data were independently extracted by two reviewers (JJE plus MK or KSD). Differences in extraction were resolved by discussion or by a third independent data extraction.

\section{Assessment of indicators}

The indicators were assessed for quality against criteria used previously, and based on the Outcome Measures in Rheumatology filter (truth, discrimination, feasibility). ${ }^{23-28}$ The assessment criteria are shown in the online supplementary text S1. Indicators were considered at the level of their development group (for the evidence synthesis, consensus exercise and testing) and at the level of the individual indicator (for discrimination and feasibility).

\section{Narrative synthesis}

The clinical reviewers (two experienced GPs-JJE and MKand an academic physiotherapist-KSD) together drafted a narrative synthesis to collate the individual indicators, which was then discussed and revised among all the authors. The indicators were mapped to OA guidance. ${ }^{3-8}$ Indicator themes developed from the best evidence and consensus method, and rated as feasible for UK primary care, were transformed into a format suitable for implementation. This included a defined numerator (the number of patients receiving a particular element of care) and denominator (those eligible for that element).

\section{RESULTS}

\section{Selection of articles}

Ten thousand eight hundred and fifty-two unique articles were identified. The final inclusion set numbered 32 . There were 10 groups of indicators in 14 development articles, and 18 implementation articles.

The Preferred Reporting Items for Systematic Reviews and Meta-Analyses (PRISMA) flow chart setting out the review process can be found in the online supplementary figure S2. Excluded studies are listed in the online supplementary table S3.

\section{Assessment of quality}

The 10 groups of studies in which indicators for OA care had been developed are listed in table 2. The following aspects of quality assessment were common to all studies and are not included in the table.

Although not every study explicitly declared there to be no conflict of interest, the reviewers considered that no significant resulting bias of the results was likely.

No studies had an identified method of updating the indicators in light of new evidence.

External validity and sensitivity to change had not been demonstrated in any of the indicator development, testing or implementation studies.

Reproducibility, at the level of the individual indicator, is shown in table 3.

Of 10 indicator development study groups, five were based on the Assessing Care of Vulnerable Elders (ACOVE) indicators. Overall, the ACOVE series of indicators were found to most closely fulfil the assessment criteria due to their robust evidence collection and consensus development, and field testing, and update in ACOVE-3. The modifications to ACOVE-1 indicators (for use the English Longitudinal Study of Aging, ${ }^{41}$ in nursing homes ${ }^{42}$ and home-based primary care ${ }^{45}$ ) were minor, such as to the target population or recommended care process time frames. The degree to which modifications were subject to further empirical study and consensus varied. We judged the modified indicators to be compatible with the originals, although there was variability regarding the indicators of use of oral non-steroidal anti-inflammatories (NSAIDs) and gastroprotective agents, in terms of the drugs recommended or the target population. The RAND indicators were the earliest identified; they were based on a literature review (not identified as systematic) and high-quality consensus exercise. The developers of the Arthritis Foundation indicators had undertaken a 'comprehensive' literature review, and a high-quality consensus exercise. One example of implementation (of the non-pharmacological indicators) was found. The remaining indicator sets used an evidence synthesis or consensus exercise which was less rigorous, or not specified. Some had no identified evidence of implementation (eg, Physician Consortium for Performance Improvement (PCPI) indicators).

All identified articles used process-of-care measures as indicators; one indicator set (European Musculoskeletal Conditions Surveillance and Information Network; EUMUSC.net) also used three outcome measures. We identified no papers in which quality improvement over time had been investigated. 


\begin{tabular}{|c|c|c|c|c|c|c|c|}
\hline \multirow{2}{*}{$\begin{array}{l}\text { Indicator set } \\
\text { Author and date }\end{array}$} & \multicolumn{2}{|l|}{ Truth } & \multirow[b]{2}{*}{ Target population } & \multirow{2}{*}{$\begin{array}{l}\text { Proposed method } \\
\text { of measurement }\end{array}$} & \multirow{2}{*}{$\begin{array}{l}\text { Testing or } \\
\text { implementation }\end{array}$} & \multirow[b]{2}{*}{ Reliability } & \multirow[b]{2}{*}{ Feasibility } \\
\hline & Evidence synthesis & Consensus method & & & & & \\
\hline $\begin{array}{l}\text { RAND Quality of } \\
\text { Care Assessment } \\
\text { Tools (RAND QA) } \\
\text { Moore }(2000)^{29}\end{array}$ & $\begin{array}{l}\text { Literature review, not } \\
\text { specified to be systematic }\end{array}$ & $\begin{array}{l}\text { RAND } \\
\text { Appropriateness } \\
\text { Method }\end{array}$ & Not specified & $\begin{array}{l}\text { Medical record } \\
\text { review }\end{array}$ & $\begin{array}{l}\text { McGlynn et } a \beta^{30} \\
\text { Asch et } a \beta^{31}\end{array}$ & $\begin{array}{l}\text { Tested in McGlynn et a }{ }^{30} \text { and Asch } \\
\text { et } \mathrm{a}^{31} \text {-in a } 4 \% \text { sample } \\
\text { reabstraction reliability was } \\
\text { substantial at } 3 \text { levels: presence of a } \\
\text { condition ( } \mathrm{\kappa}=0.83 \text { ), indicator eligibility } \\
(\mathrm{\kappa}=0.76) \text { and indicator scoring } \\
\mathrm{K}=0.80)\end{array}$ & $\begin{array}{l}\text { McGlynn et a } a^{30} \text { use a national sample } \\
\text { of US citizens in metropolitan areas, } \\
\text { using a telephone interview to collect } \\
\text { data with subsequent analysis of } \\
\text { medical records where consent was } \\
\text { given. Asch et } a^{31} \text { use the same data } \\
\text { as a comparator for data collected from } \\
\text { a random sample of veterans' health } \\
\text { affairs clients and their records }\end{array}$ \\
\hline $\begin{array}{l}\text { ACOVE -1 } \\
\text { MacLean } \\
(2001)^{32} 33\end{array}$ & $\begin{array}{l}\text { Systematic review supporting } \\
\text { indicators produced by a } \\
\text { content expert working with } \\
\text { a project member } \\
\text { knowledgeable about } \\
\text { systematic reviews and } \\
\text { quality indicator } \\
\text { development }\end{array}$ & $\begin{array}{l}\text { Modified RAND/ } \\
\text { UCLA } \\
\text { Appropriateness } \\
\text { Method }\end{array}$ & $\begin{array}{l}\text { 'Vulnerable elders'-persons } \\
\geq 65 \text { years who are at } \\
\text { increased risk for death or } \\
\text { functional decline }\end{array}$ & Not specified & $\begin{array}{l}\text { Wenger et al } \\
\text { Chodosh et al } \\
\text { Higashi et }\left.a\right|^{36} 37 \\
\text { Ganz et a }{ }^{38} \\
\text { MacLean et a }\left.a\right|^{39} \\
\text { Østerås et } a l^{40}\end{array}$ & 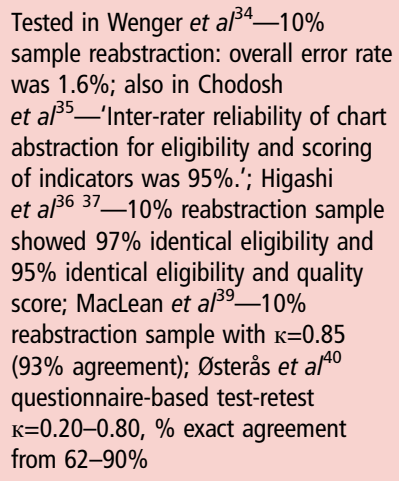 & $\begin{array}{l}\text { Wenger et a } a^{34} \text { implemented the } \\
\text { indicators in community dwelling VEs } \\
\text { in the USA-medical record abstraction } \\
\text { by trained nurses supplemented for } \\
\text { some indicators by telephone } \\
\text { interview. Chodosh et al, }{ }^{35} \text { Higashi } \\
\text { et } a^{36}{ }^{37} \text { and MacLean et al }\left.\right|^{39} \text { used the } \\
\text { same population and methods. Ganz } \\
\text { et al used a similar population and } \\
\text { methodology at a different time point }{ }^{38} \\
\text { Østerås et a } a^{40} \text { implemented some of } \\
\text { these indicators in a patient self-report } \\
\text { format }\end{array}$ \\
\hline $\begin{array}{l}\text { ACOVE-1 adapted } \\
\text { for the ELSA } \\
\text { Steel et al }(2004)^{41}\end{array}$ & $\begin{array}{l}\text { Transposition of previous } \\
\text { ACOVE work (referenced). } 26 \\
\text { new indicators for the set } \\
\text { were suggested by the panel }\end{array}$ & $\begin{array}{l}\text { Modified RAND/ } \\
\text { UCLA } \\
\text { Appropriateness } \\
\text { Method }\end{array}$ & $\begin{array}{l}\text { Older patients in the UK } \\
\geq 65 \text { years) }\end{array}$ & $\begin{array}{l}\text { Interviews for the } \\
\text { ELSA }\end{array}$ & $\begin{array}{l}\text { Steel et al, }{ }^{12} 14 \\
\text { Broadbent et al } l_{13}^{13} \\
\text { Østerås et } a l^{40}\end{array}$ & $\begin{array}{l}\text { Tested in Steel et } \mathrm{al}^{12}-(\mathrm{\kappa}=0.8,95 \% \\
\mathrm{Cl}=0.7 \text { to } 0.9) ; \text { Østerås et a } \mathrm{a}^{40} \\
\text { questionnaire-based test-retest } \\
\mathrm{K}=0.20-0.80, \% \text { exact agreement } \\
\text { from } 62-90 \%\end{array}$ & $\begin{array}{l}\text { Broadbent et al }{ }^{13} \text { and Steel et } a^{12} \\
\text { separately implemented indicators in } \\
\text { UK general practice, using medical } \\
\text { record review (computerised and paper } \\
\text { notes). } \\
\text { Østerås et a } a^{40} \text { implemented some of } \\
\text { these indicators in a patient self-report } \\
\text { format }\end{array}$ \\
\hline $\begin{array}{l}\text { ACOVE-1 adapted } \\
\text { for NH } \\
\text { implementation } \\
\text { (ACOVE/NH) } \\
\text { Saliba et al } \\
(2005)^{42}\end{array}$ & $\begin{array}{l}\text { Previous referenced (ACOVE) } \\
\text { work, plus expert opinion } \\
\text { (for modification) and } \\
\text { additional indicator } \\
\text { development, methodology } \\
\text { not specified in detail }\end{array}$ & $\begin{array}{l}\text { Modified Delphi; } \\
\text { subsequent overview } \\
\text { by ACOVE clinical } \\
\text { committee }\end{array}$ & $\begin{array}{l}\text { Long-stay NH residents } \\
\geq 65 \text { years Exclusions for } \\
\text { advanced dementia or poor } \\
\text { prognosis }\end{array}$ & Not specified & $\begin{array}{l}\text { Cadogan et } a l^{43} \\
\text { Zingmond et al }\left.\right|^{44}\end{array}$ & $\begin{array}{l}\text { Tested in Cadogan et } a /{ }^{43}-\kappa=0.65- \\
1.00 \text { and percentage agreement } 80- \\
100 \text { where } \kappa \text { could not be calculated } \\
\text { (numbers too low) }\end{array}$ & $\begin{array}{l}\text { Cadogan et a } a^{43} \text { implemented } \\
\text { indicators in } 30 \text { nursing homes in } \\
\text { California using medical record review. } \\
\text { Zingmond et a } a^{44} \text { implemented using } \\
\text { Medicare and Medicaid eligibility and } \\
\text { claims data and a nursing home } \\
\text { minimum dataset }\end{array}$ \\
\hline $\begin{array}{l}\text { ACOVE-1 adapted } \\
\text { for the HPCQI } \\
\text { Smith et al } \\
(2007)^{45}\end{array}$ & $\begin{array}{l}\text { Based on ACOVE indicators, } \\
\text { plus some additional } \\
\text { (non-OA) indicators. ACOVE } \\
\text { work referenced; additional } \\
\text { expert opinion }\end{array}$ & $\begin{array}{l}\text { Modified Delphi } \\
\text { techniques }\end{array}$ & $\begin{array}{l}\text { Patients } \geq 60 \text { years who are } \\
\text { homebound }\end{array}$ & Not specified & $\begin{array}{l}\text { No published } \\
\text { examples of testing } \\
\text { identified }\end{array}$ & No reliability testing identified & No feasibility testing identified \\
\hline $\begin{array}{l}\text { ACOVE-3 } \\
\text { ACOVE } \\
\text { investigators } \\
(2007)^{46-48}\end{array}$ & $\begin{array}{l}\text { A systematic review } \\
\text { supporting potential } \\
\text { indicators produced by a } \\
\text { content expert working with }\end{array}$ & $\begin{array}{l}\text { Modified version of } \\
\text { the RAND/UCLA } \\
\text { Appropriateness } \\
\text { Method }\end{array}$ & $\begin{array}{l}\text { Community-dwelling } \\
\text { individuals aged } \geq 65 \text { years } \\
\text { who are at greater risk of }\end{array}$ & $\begin{array}{l}\text { Medical records and/ } \\
\text { or administrative } \\
\text { data, patient or } \\
\text { proxy interview }\end{array}$ & Østerås et a $\left.\right|^{40}$ & $\begin{array}{l}\text { Østerås et a }\left.\right|^{40} \text { questionnaire-based } \\
\text { test-retest } \kappa=0.20-0.80, \% \text { exact } \\
\text { agreement from } 62-90 \%\end{array}$ & $\begin{array}{l}\text { Østerås et a }{ }^{40}{ }^{4} \text { implemented some of } \\
\text { these indicators in a modified patient } \\
\text { self-report format }\end{array}$ \\
\hline
\end{tabular}




\section{Table 2 Continued}

\begin{tabular}{|c|c|c|c|c|c|c|c|}
\hline \multirow{2}{*}{$\begin{array}{l}\text { Indicator set } \\
\text { Author and date }\end{array}$} & \multicolumn{2}{|l|}{ Truth } & \multirow[b]{2}{*}{ Target population } & \multirow{2}{*}{$\begin{array}{l}\text { Proposed method } \\
\text { of measurement }\end{array}$} & \multirow{2}{*}{$\begin{array}{l}\text { Testing or } \\
\text { implementation }\end{array}$} & \multirow[b]{2}{*}{ Reliability } & \multirow[b]{2}{*}{ Feasibility } \\
\hline & Evidence synthesis & Consensus method & & & & & \\
\hline & $\begin{array}{l}\text { a project member } \\
\text { knowledgeable about } \\
\text { systematic reviews and } \\
\text { indicator development }\end{array}$ & & $\begin{array}{l}\text { death or functional decline } \\
\text { over a 2-year period }\end{array}$ & & & & \\
\hline $\begin{array}{l}\text { QIGP } \\
\text { Underwood } \\
(2002)^{49}\end{array}$ & $\begin{array}{l}\text { Various sources used } \\
\text { (Cochrane, DARE, Medline) } \\
\text { but not clear how the } \\
\text { evidence was assembled. } \\
\text { Cites meta-analyses, } \\
\text { systematic reviews, } \\
\text { randomised controlled trials }\end{array}$ & Not stated & Not specified & Not specified & $\begin{array}{l}\text { Kirk et al }{ }^{50} \\
\text { Steel et } a l^{12} \\
\text { Broadbent et a }\left.\right|^{13} \\
\text { Østerås et } a l^{40}\end{array}$ & $\begin{array}{l}\text { Tested for non-OA indicators in Kirk } \\
\text { et al }{ }^{50} \text {-as } \mathrm{OA} \text { was not included in } \\
\text { this exercise, it is not known what } \\
\text { degree of reliability exists for these } \\
\text { indicators; Østerås et al }{ }^{40} \\
\text { questionnaire-based test-retest } \\
\mathrm{K}=0.20-0.80, \% \text { exact agreement } \\
\text { from } 62-90 \%\end{array}$ & $\begin{array}{l}\text { Kirk et } a l^{50} \text { implemented in } 16 \text { UK } \\
\text { general practices in two areas using } \\
\text { data from electronic and paper records. } \\
\text { Steel et } a l^{12} \text { and Broadbent } e t a l^{13} \\
\text { separately implemented the NSAID } \\
\text { indicator in UK general practice, using } \\
\text { medical record review (computerised } \\
\text { and paper notes). } \\
\text { Østerås et al } l^{40} \text { implemented some of } \\
\text { these indicators in a modified patient } \\
\text { self-report format }\end{array}$ \\
\hline $\begin{array}{l}\text { Arthritis } \\
\text { Foundation } \\
\text { Arthritis } \\
\text { Foundation } \\
2004^{5152}\end{array}$ & $\begin{array}{l}\text { Comprehensive literature } \\
\text { search and expert opinion }\end{array}$ & $\begin{array}{l}\text { Modified RAND/ } \\
\text { UCLA } \\
\text { Appropriateness } \\
\text { Method }\end{array}$ & Patients with $\mathrm{OA}$ & Not specified & Li et $a P^{53}$ & No reliability testing identified & $\begin{array}{l}\text { Li et a } a^{53} \text { used a postal survey in } \\
\text { Canada (sampling frame from an } \\
\text { administrative database in British } \\
\text { Columbia) to assess } \\
\text { non-pharmacological indicators }\end{array}$ \\
\hline PCPI $(2006)^{54}$ & \multicolumn{2}{|c|}{$\begin{array}{l}\text { PCPI website refers to a methodology committee but } \\
\text { no specific information in the indicator set to identify } \\
\text { how it was developed }\end{array}$} & $\begin{array}{l}\text { All patients aged } \geq 21 \text { years } \\
\text { with a diagnosis of } \mathrm{OA}\end{array}$ & $\begin{array}{l}\text { Medical record data } \\
\text { extraction (detailed } \\
\text { numerator and } \\
\text { denominator } \\
\text { information } \\
\text { provided) }\end{array}$ & $\begin{array}{l}\text { No published } \\
\text { examples of testing } \\
\text { identified }\end{array}$ & No reliability testing identified & No feasibility testing identified \\
\hline $\begin{array}{l}\text { EUMUSC.net } \\
(2012)^{55}\end{array}$ & \multicolumn{2}{|c|}{$\begin{array}{l}\text { Developed from the EUMUSC.net standards of care } \\
\text { for } \mathrm{OA} \text { and refined by researchers and patient } \\
\text { representatives }\end{array}$} & $\begin{array}{l}\text { All adult patients with } \mathrm{OA} \text { of } \\
\text { hand, hip or knee }\end{array}$ & $\begin{array}{l}\text { Varies. Examples } \\
\text { include patient } \\
\text { record or survey. } \\
\text { Numerator and } \\
\text { denominator clearly } \\
\text { identified }\end{array}$ & $\begin{array}{l}\text { No published } \\
\text { examples of testing } \\
\text { identified }\end{array}$ & No reliability testing identified & No feasibility testing identified \\
\hline
\end{tabular}

ACOVE, Assessing Care of Vulnerable Elders; DARE, Database of Abstracts of Reviews of Effects; ELSA, English Longitudinal Study of Ageing; EUMUSC.net, European Musculoskeletal Conditions Surveillance and Information Network; HPCQI, Home-based Primary Care Quality Initiative; NH, nursing home; NSAIDs, non-steroidal anti-inflammatories; OA, osteoarthritis, PCPI, Physician Consortium for Performance Improvement; QIGP, Quality Indicators for General Practice; UCLA, University of California, Los Angeles; VE, vulnerable elder. 
Table 3 Narrative synthesis of exemplar indicators and their feasibility for use in primary care

Overarching theme (source)

Holistic Assessment: Pain

(EULAR (all sites), NICE)

Holistic Assessment: Function (ACR (hand), EULAR (all sites) NICE )

Education (EULAR (all sites),

NICE, OARSI)

Exercise 1 and 2 (ACR (hip

knee), EULAR (all sites), NIC

OARSI

'Exemplar' indicator

IF a VE has symptomatic OA of the knee or hip, THEN pain should be assessed when new to a primary care or musculoskeletal disease practice and annually... (ACOVE-3) ${ }^{46-48}$

IF a VE has symptomatic OA of the knee or hip, THEN functional status should be assessed when new to a primary care or musculoskeletal disease practice and annually...(ACOVE-3) ${ }^{46}$

IF a patient has had a diagnosis of symptomatic $\mathrm{OA}$ of the knee or hip for $>3$ months, THEN education about the natural history, treatment, and self-management of $\mathrm{OA}$ should have been given or recommended at least once. (Arthritis Foundation) ${ }^{51} 52$

IF an ambulatory VE has symptomatic $\mathrm{OA}$ of the knee or hip for longer than 3 months and is able to exercise, THEN a directed or supervised muscle strengthening or aerobic exercise program should be recommended and activity reviewed annually...(ACOVE-3) ${ }^{46-48}$

Weight loss 1 (ACR (hip knee), NICE, OARS

IF a VE is obese (body mass index (BMI) $\geq 30 \mathrm{~kg} / \mathrm{m}^{2}$ ), THEN he or she should be advised annually to lose weight... (ACOVE-3) ${ }^{46-48}$

Weight loss 2 (ACR (hip knee), NICE, OARS

IF a patient has symptomatic $\mathrm{OA}$ of the knee or hip and is overweight (as defined by body mass index of $\geq 27 \mathrm{~kg} / \mathrm{m}^{2}$ ), THEN the patient should be advised to lose weight at least annually AND the benefit of weight loss on the symptoms of $\mathrm{OA}$ should be explained to the patient... (Arthritis Foundation) $)^{51}$

Aids and devices 1 (ACR (hip, IF a VE has symptomatic OA of the hip or knee and has difficulty walking knee), EULAR (hip, knee),

NICE, OARSI)

Aids and devices 2 (ACR

(hand), NICE)

that makes ADL difficult for longer than 3 months, THEN the need for ambulatory assistive devices should be assessed...(ACOVE-3) (6-48 $^{46}$

IF a VE has symptomatic $O A$ and has difficulty with non-ambulatory ADL, THEN the need for ADL assistive devices should be assessed... $(\text { ACOVE-3) })^{46-48}$

Paracetamol 1 (ACR (hip

IF a VE is started on pharmacological therapy to treat OA, THEN knee), EULAR (all sites), NICE, acetaminophen should be tried first... (ACOVE-3) ${ }^{46-48}$

OARSI)

Paracetamol 2 (ACR (hip

knee), EULAR (all sites), NICE,

OARSI)

Oral NSAIDs 1 (all guidance)

Oral NSAIDs 2 (all guidance)

IF oral pharmacological therapy for $\mathrm{OA}$ is changed from acetaminophen to different oral agent, THEN there should be evidence that the patient has

had a trial of maximum dose acetaminophen (suitable for age/

comorbidities)....(Arthritis Foundation) $)^{51}$

If NSAIDs are considered, ibuprofen should be considered for first-line treatment unless contraindicated or intolerant. ${ }^{*}(\mathrm{QIGP})^{49}$

Percentage of patients aged 21 years and older with a diagnosis of $\mathrm{OA}$ on prescribed or OTC NSAIDs who were assessed for GI and renal risk factors. $(\mathrm{PCPI})^{54}$

Reproducibility (other sources of similar indicators)

RAND QA, ${ }^{29}$ ACOVE-1, ${ }^{32}{ }^{33}$ and as adapted (ELSA, ${ }^{41}$

HPCQI ${ }^{45}$ ), Arthritis Foundation, ${ }^{51}{ }^{52} \mathrm{PCPI}^{54}$ EUMUSC.

net $^{55}$

RAND QA ${ }_{1}^{29}$ ACOVE- $1,{ }^{32} 33$ and as adapted (ELSA, ${ }^{41}$

$H P\left(I^{45}\right)$, Arthritis Foundation, ${ }^{51}{ }^{52} \mathrm{PCPI}^{54}$

ACOVE-1 (2 variations - new and pre-existing

disease), ${ }^{32} 33$ and as adapted (ELSA ${ }^{41}$ ), EUMUSC.net ${ }^{55}$

Initial recommendation

RAND QA ${ }^{29}$ ACOVE-1 (indicators for new and

pre-existing disease), ${ }^{32} 33$ and as adapted (ELSA, ${ }^{41}$

ACOVE/NH, $\left.{ }^{42} \mathrm{HPCQ}^{45}\right)$, Arthritis Foundation, ${ }^{51}{ }^{1}$

PCPI ${ }^{54}$ EUMUSC.net ${ }^{55}$

Annual review

RAND QA ${ }^{29}$ ACOVE-1 ${ }^{32}{ }^{33}$

Arthritis Foundation ${ }^{51} 52$

EUMUSC.net ${ }^{55}$

Arthritis Foundation, ${ }^{51}{ }^{52}$ EUMUSC.net ${ }^{55}$

Arthritis Foundation, ${ }^{51}{ }^{52}$ EUMUSC.net ${ }^{55}$

RAND QA ${ }^{29}$ ACOVE-1, 3233 and as adapted (ELSA,

ACOVE/NH ${ }^{42} \mathrm{HPCQI}^{45}$ ), QIGP, ${ }^{49}$ Arthritis

Foundation, ${ }^{51} 52$

ACOVE-1, ${ }^{32}{ }^{33}$ and as adapted (ELSA, ${ }^{41}$ ACOVE/NH, ${ }^{42}$ HPCQI ${ }^{45}$ )

Modifications exist in implementation studies: Steel et $\mathrm{al}_{,^{12}}$ Broadbent et $\mathrm{ll}^{13}$ to include use of COX-2 selective drugs

Two indicators from ACOVE-3 refer to risks from NSAIDs and aspirin to be 'discussed and documented', ${ }^{46-48}$ EUMUSC.net ${ }^{55}$
Implementation references and comment on feasibility

1213303134353840

Requires change in routine coding to improve capture of this information

12133031353840

Requires change in routine coding to improve capture of this information

$12-143438$

Requires change in routine coding to improve capture of this information

\section{Initial recommendation}

Annual review

Requires change in routine coding to improve capture of this information

No implementation studies identified for this indicator.

Should be captured from existing weight and health promotion records

4053

Consider a lower BMI threshold of $25 \mathrm{~kg} / \mathrm{m}^{2}$ for consistency with the usual definition of 'overweight'. Should be captured from existing weight and health promotion records.

405

Requires change in routine coding to improve capture of this information

Requires change in routine coding to improve capture of this information

12-1430313436-38 40 4350

Requires change in routine coding to capture over-the-counter drug use

1213343643

Requires change in routine coding to capture over-the-counter drug use

121350

Requires change in routine coding to capture over-the-counter drug use.

1213

Requires change in routine coding to capture over-the-counter drug use 


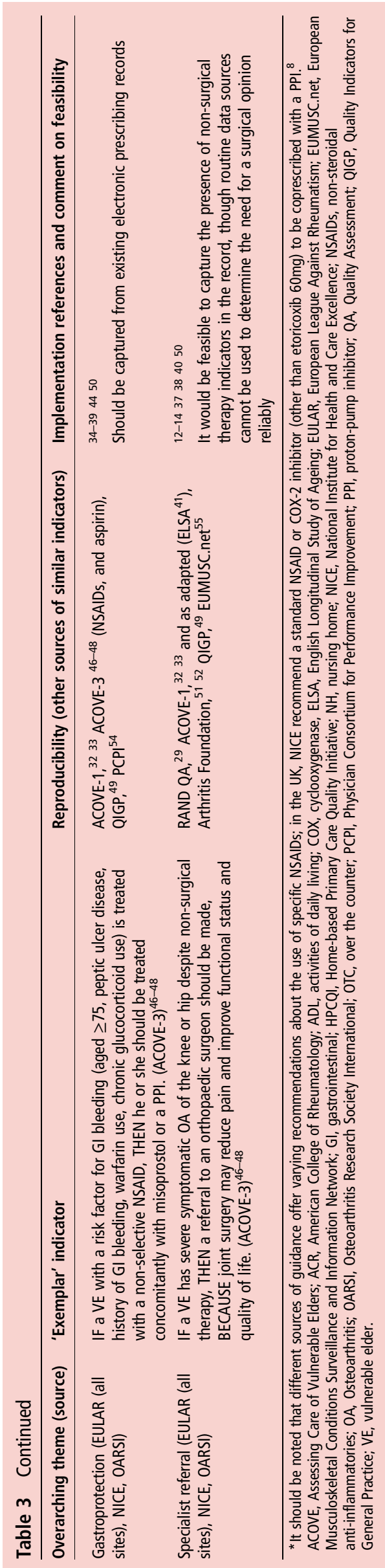

Narrative synthesis

The indicators identified in the studies were grouped into themes. A summary of exemplar indicators is shown in table 3. The basis of the exemplar choice from the truth and feasibility aspects of the evidence is shown (discrimination was not found to be empirically supported). A list of indicators suitable for routine implementation in primary care is shown in table 4 . Online supplementary table S4 lists indicators which do not currently provide sufficient evidence or feasibility for implementation in primary care.

1. Holistic assessment

There were 28 occurrences of indicators related to holistic assessment of patients.

Assessments of pain and function were relatively frequent. The ACOVE-3 examples were rated most highly. Exemplar indicators have been selected for these elements of care. Indicators for joint examination and joint aspiration arose less frequently, though were still the result of at least one high quality evidence synthesis and consensus exercise, but had not successfully been implemented.

2. Education and information

There were 18 occurrences of indicators for education in OA. The Arthritis Foundation indicator was selected due to its cited evidence synthesis and consensus method, and its consistency with the previously implemented ACOVE- 1 and recently published EUMUSC.net indicators; no education indicator was included in ACOVE-3. There was some variation in the timeframes specified for education. It was not clear from most studies implementing this indicator theme how the required level of detail about type of education was obtained. For example, one study asked the patient in a telephone interview "Has any doctor or nurse ever talked to you about: (1) What your arthritis or joint pain will be like as time goes on, or the natural history of arthritis?, (2) How to keep your arthritis or joint pain from getting worse?, (3) How your arthritis can be treated?"38; a criterion to pass the indicator was at least one positive response. Evidence from implementation studies suggests that the indicator as worded is less feasible for implementation in primary care, requiring either a more generic indicator or a series of specific patient self-report indicators; we propose a more generic indicator.

The EUMUSC.net team includes an education indicator aimed at clinicians, which we did not include as it is not a patient-focused indicator.

3. Exercise and physiotherapy

There were 22 occurrences of indicators recommending or prescribing exercise or physiotherapy. One targeted patients with hand, hip and knee $\mathrm{OA}^{55}$; one self-report indicator implemented also included patients with hand, hip or knee $\mathrm{OA}^{40}$; six refer to exercise for patients with $\mathrm{OA}$ of the hip or knee; the remainder specify those with knee OA. There were variations between indicators on exercise, with some recommending that a programme be 'prescribed', 'recommended' or 'considered'. Some referred to specific strengthening programmes, others to general aerobic exercise, or physical therapy. For example, one study used a record of prescription for lower extremity strengthening or ambulation with a Physical Therapist or Restorative Nursing Assistant after OA diagnosis as a criterion ${ }^{43}$; others used non-routine sources such as patient interview or unspecified sources. Evidence from implementation studies suggests that feasible indicators for primary care relate to the offer of exercise advice or physiotherapy referral, and review of current exercise activity. It would be feasible to separate two elements of the ACOVE-3 indicator into an indicator for advice, 
Table 4 Proposed indicators for primary care implementation

\begin{tabular}{|c|c|}
\hline Overarching theme & Proposal for primary care implementation \\
\hline Holistic Assessment: Pain & $\%$ patients with a working diagnosis of $\mathrm{OA}$ with evidence of pain assessment within the previous 12 months \\
\hline $\begin{array}{l}\text { Holistic Assessment: } \\
\text { Function }\end{array}$ & $\%$ patients with a working diagnosis of OA with evidence of function assessment within the previous 12 months \\
\hline Education & $\%$ patients with a working diagnosis of $\mathrm{OA}$ with evidence of education or advice since diagnosis \\
\hline Exercise 1 & $\%$ patients with a working diagnosis of $\mathrm{OA}$ in the hip or knee with evidence of exercise advice or physiotherapy referral since diagnosis \\
\hline Exercise 2 & $\%$ patients with a working diagnosis of $\mathrm{OA}$ with evidence of an activity review within the previous 12 months \\
\hline Weight loss 1 & $\%$ patients with a $\mathrm{BMI} \geq 30 \mathrm{~kg} / \mathrm{m}^{2}$ who have a record of weight loss advice within the previous 12 months \\
\hline Weight loss 2 & $\%$ patients with a working diagnosis of $\mathrm{OA}$ with a $\mathrm{BMI} \geq 25 \mathrm{~kg} / \mathrm{m}^{2}$ who have a record of weight loss advice within the previous 12 months \\
\hline Aids and devices 1 & $\begin{array}{l}\% \text { patients with a working diagnosis of } \mathrm{OA} \text { with evidence of functional impairment who are recorded as receiving a referral or assessment for } \\
\text { ambulatory assistive devices within the previous } 12 \text { months }\end{array}$ \\
\hline Aids and devices 2 & $\begin{array}{l}\% \text { patients with a working diagnosis of } \mathrm{OA} \text { with evidence of functional impairment who are recorded as receiving a referral or assessment for } \\
\text { assistive devices within the previous } 12 \text { months }\end{array}$ \\
\hline Paracetamol 1 & $\%$ patients with a working diagnosis of $\mathrm{OA}$ with evidence of paracetamol as the first oral analgesic prescribed or advised since diagnosis \\
\hline Paracetamol 2 & $\begin{array}{l}\% \text { patients with a working diagnosis of OA taking oral analgesics or NSAIDs with evidence that a suitable maximal dose of paracetamol was } \\
\text { tried beforehand }\end{array}$ \\
\hline Oral NSAIDs 1 & $\begin{array}{l}\% \text { patients with a working diagnosis of OA with evidence of a standard NSAID or COX-2 inhibitor as the first oral NSAID prescribed or advised } \\
\text { since diagnosis }\end{array}$ \\
\hline Oral NSAIDs 2 & $\%$ patients with a working diagnosis of OA taking an oral NSAID with a documented risk assessment prior to first prescription \\
\hline Gastroprotection & $\%$ patients with a working diagnosis of OA taking an oral NSAID who are also prescribed a PPI or alternative gastroprotective agent \\
\hline Specialist assessment & $\%$ patients with a record of achievement of all other applicable indicators prior to specialist referral* \\
\hline
\end{tabular}

recommendation or prescription of exercise, and an indicator of annual review of activity.

\section{Weight management}

There were eight occurrences of indicators regarding weight loss in overweight patients, six for patients with OA and two for primary prevention. There was some variation in the BMI intervention threshold as well as in the type of advice or referral. There were two implementation studies identified, of the Arthritis Foundation indicator regarding weight management in symptomatic OA, in which Li et $a l^{53}$ used entry to a weight-loss programme or dietetics appointment as criteria for indicator achievement and the weight loss advice self-report indicator in Østerås $e$ t $a l^{40} \mathrm{~A}$ primary care indicator related to advice regarding weight loss to reduce the risk of OA, or to improve symptoms in people with established OA would be feasible. A further identified indicator, regarding referral to a weight-loss programme if a person has been overweight for 3 years or more, would be less feasible and desirable, due to greater difficulty establishing the denominator population.

5. Assistive devices (ambulatory and other)

There were nine occurrences of indicators for assessment of need for assistive devices. These covered assessment of need for ambulatory and non-ambulatory assistive devices but there were no specifically recommended interventions. Two examples of implementation were found, of Arthritis Foundation indicators (similar to and consistent with the ACOVE-3 indicators) by $\mathrm{Li}$ et $a l,,^{53}$ in which credit was given when a patient had seen a physiotherapist or occupational therapist for ambulatory or nonambulatory devices respectively within the previous year, and similar patient self-report indicators in Østerås et al. ${ }^{40}$ In line with this, general indicators for referral or assessment for ambulatory or assistive devices currently appear feasible in primary care.

6. Analgesics (paracetamol and oral NSAIDs)

There were 53 occurrences of indicators for use of analgesics in OA. These covered topics such as assessment of current use or consideration of analgesics; use of appropriate first-line analgesics; and risk assessment and communication. Preferred indicators generally result from at least one high quality evidence synthesis and consensus exercise, although the basis for the NSAID risk assessment indicator from the PCPI is unclear ${ }^{54}$ (though consistent with a similar indicator from the ACOVE-1 group). Where available, the ACOVE-3 indicators were chosen. Several indicators regarding use of paracetamol and NSAIDs are considered feasible for use in primary care (see table 3). Indicators regarding assessment of existing use and consideration of additional treatment from the $\mathrm{PCPI}^{54}$ and an implemented indicator regarding stronger analgesics (Østerås et $a l^{40}$ ) were not selected due to an unspecified evidence base and consensus approach; indicators regarding risk explanation were also not selected due to difficulties implementing these in routine data sources (without free text medical record analysis).

7. Gastroprotection

There were 13 occurrences of indicators for use of gastroprotective agents under certain conditions. However, there were variations in the triggers for prescribing a gastroprotective agent, and in the choice of agent to be used. The broadest (PCPI) indicator ${ }^{54}$ cites a meta-analysis as having indicated that use of gastrointestinal prophylaxis can be effective in reducing the incidence of adverse events. This would be consistent with the NICE recommendation that everyone over 45 years prescribed a NSAID for OA should be coprescribed a proton pump inhibitor. ${ }^{8}$ Where indicators have been implemented, they often use past medical history or co-therapy with other agents (eg, aspirin or warfarin) to determine the denominator group for this indicator. The PCPI indicator is the most feasible, although this has been narrowed to include only proton-pump inhibitor gastroprotection in line with NICE guidance.

8. X-rays, injections, specialist assessment and joint replacement

There were 16 instances of indicators for referral to a specialist and use of X-rays when symptoms were not improving under non-surgical care. As guidance for management of OA does not recommend routine use of X-rays, and no examples of implementation of X-ray indicators was found, this indicator was not considered feasible. A number of indicators referred to failure 
of other therapies as a prerequisite for specialist referral but 'failure' was not consistently defined. One study asked patients if they had pain and functional impairment, and had been offered a joint replacement or orthopaedic assessment. ${ }^{38}$ Another used a patient self-report to identify failure of conservative treatment leading to referral. ${ }^{40} \mathrm{An}$ indicator mandating that all other indicators must have been recorded as appropriately met prior to referral was considered to be feasible.

There was also one indicator implemented for the consideration of steroid injections for acute symptomatic deterioration. ${ }^{40}$ This was not considered feasible for routine implementation in primary care since acute deterioration is hard to identify from the record and many injections take place in secondary care.

9. Outcome measure indicators

The EUMUSC.net project also identified three outcome measures ${ }^{55}$ :

- a $20 \%$ functional improvement within 3 months of a treatment initiation or change

- a $20 \%$ reduction in pain within 3 months of a treatment initiation or change

- enablement of workforce participation for people of working age.

These were considered less feasible for primary care due to the complexity of accounting for comorbidities and case-mix.

\section{DISCUSSION}

Through a systematic review of $\mathrm{OA}$ indicators and a quality appraisal of the indicator development and implementation, we identified 15 indicators of the quality of primary care for OA which could be implemented, benefiting patients, clinicians and policy development.

While the conclusions of the published guidance diverge in some aspects (particularly the use of Symptomatic Slow-Acting Drugs in Osteo-Arthritis, and in some of the detail of oral NSAID use and gastroprotection), the interventions recommended by the different expert groups are broadly similar. The selected indicators were broadly applicable across all the guidance groups.

Within themes, there are differences between some of the identified indicators. Indicators sometimes target differing populations (eg, OA of the knee or any OA), frequency or threshold of assessment or intervention, type of treatment (eg, variation in oral NSAID recommended, and type of gastroprotective agent). These differences are not sufficiently major to cause difficulties in the implementation of the underlying indicator theme.

There are some limitations in this review. There may be indicators not captured by the search strategy (including any prior to 2000 , and non-English language indicators). Given the thorough nature of the indicator development methodology for a number of the indicator sets, it seems unlikely that any major themes will have been omitted. In contrast with the assessment of publications on randomised controlled trials (eg, the approach taken by the Cochrane Collaboration), quality assessment of indicators themselves is not a highly developed methodology. ${ }^{56}$

We have selected indicators judged sufficiently robust and feasible for use in routine practice. The use of indicators is dependent upon systematic information capture. In the UK, approximately $90 \%$ of prescriptions are obtained with no cost to the patient, and over-the-counter analgesics are restricted in quantity. ${ }^{57}$ Analgesics and NSAIDs indicators based on data from computer-generated prescriptions are likely to be valid with no change to recording practice. Other indicators would require a change in coding practice (more detailed coded clinical information). The indicators should be generally applicable to countries with well-developed primary care systems and electronic medical records. The indicators would work best with strategic implementation, for example by inclusion in the Quality and Outcomes Framework of pay-for-performance in UK primary care. ${ }^{58}$

While there are some domains with well-developed and valid indicators, some elements do not have such indicators. For example (1) Holistic assessment: all dimensions other than pain and function, notably periodic review, a jointly formulated management plan and the effect of comorbidities; (2) Education and self-management: the development of a self-management plan and thermotherapy; (3) Non-pharmacological management: manipulation and stretching, electrotherapy, bracing, joint supports, footwear and insoles; and (4) Pharmacological management: topical NSAIDs, capsaicin and intra-articular injections. In principle, some of these areas might be suitable for the development of indicators.

We did not identify any negative ('do not do') indicators. There are some areas of guidance from which one might usefully derive such indicators for use in primary care. For example, the use of topical rubefacients, electroacupuncture, nutraceuticals, or intra-articular hyaluronan injections, or referral for arthroscopic lavage for OA, based on the NICE guidance. ${ }^{8}$

We found no evidence of external validity (that implementation of indicators is associated with quality improvement). Also, there is no evidence of indicators' sensitivity to change, so this must currently be assumed. The degree to which a change in recording of the care processes actually reflects a change in the quality of care delivered has not clearly been identified. These areas warrant further investigation: an increased use of patient-reported measures such as those used by Østerås $e t a l^{40}$ would help identify changes in process delivery and outcome.

We have identified a range of indicators for OA which have a good evidence base, are consistent with international guidance, and many of which have been implemented previously. As the disease burden of OA is high, and much of it is presented clinically to GPs, incorporation of these indicators to routine primary care practice is recommended.

Acknowledgements The authors wish to thank the anonymous reviewers of the manuscript for their insightful and helpful observations; also Professor Peter Croft, Professor Danielle van der Windt and Dr Olalekan Uthman, of the Arthritis Research UK Primary Care Centre at Keele University for comments on an earlier draft of this manuscript.

Contributors KSD developed the idea for the review. JJE and JU designed the search strategy. JJE, MK and KSD analysed the papers and extracted the data. All authors contributed to the analysis and revised the paper. JJE is the guarantor.

Funding This report is independent research arising from an In-Practice Fellowship supported by the National Institute for Health Research (NIHR) with additional funding from the NIHR Programme Grants for Applied Research Programme (Grant Reference Number RP-PG-0407-10386). The views expressed in this publication are those of the authors and not necessarily those of the NHS, the National Institute for Health Research or the Department of Health.

Competing interests All authors have completed the ICMJE uniform disclosure form at http://www.icmje.org/coi_disclosure.pdf (available on request from the corresponding author) and declare: no support from any organisation for the submitted work other than detailed above; JJE, MK and JB provide general medical services and benefit financially from the Quality and Outcomes Framework (which does not currently include osteoarthritis), KSD has been an invited speaker to the EULAR conference and a member of the NICE OA guideline development groupKeele University have received payments and reimbursements of travel and other expenses related to these activities. There are no other financial relationships with any organisations that might have an interest in the submitted work in the previous 3 years. There are no other relationships or activities that could appear to have influenced the submitted work. 
Provenance and peer review Not commissioned; externally peer reviewed.

Open Access This is an Open Access article distributed in accordance with the Creative Commons Attribution Non Commercial (CC BY-NC 3.0) license, which permits others to distribute, remix, adapt, build upon this work non-commercially, and license their derivative works on different terms, provided the original work is properly cited and the use is non-commercial. See: http://creativecommons.org/ licenses/by-nc/3.0/

\section{REFERENCES}

1 RCGP Birmingham Research Unit. Weekly Returns Service Annual Prevalence Report 2007. http://www.rcgp.org.uk/clinical-and-research/ /media/Files/CIRC/CIRC\% 2076\%20-\%2080/BRU_Annual_prevalence_report_2007.ashx

2 National Collaborating Centre for Chronic Conditions. Osteoarthritis: national clinical guideline for care and management in adults. London: Royal College of Physicians, 2008.

3 Hochberg MC, Altman RD, April KT, et al. American College of Rheumatology 2012 recommendations for the use of nonpharmacologic and pharmacologic therapies in osteoarthritis of the hand, hip, and knee. Arthritis Care Res 2012;64:465-74.

4 Jordan KM, Arden NK, Doherty M, et al. EULAR Recommendations 2003: an evidence based approach to the management of knee osteoarthritis: Report of a Task Force of the Standing Committee for International Clinical Studies Including Therapeutic Trials (ESCISIT). Ann Rheum Dis 2003;62:1145-55.

5 Zhang W, Doherty M, Arden N, et al. EULAR evidence based recommendations for the management of hip osteoarthritis: report of a task force of the EULAR Standing Committee for International Clinical Studies Including Therapeutics (ESCISIT). Ann Rheum Dis 2005;64:669-81.

6 Zhang W, Doherty M, Leeb BF, et al. EULAR evidence based recommendations for the management of hand osteoarthritis: report of a Task Force of the EULAR Standing Committee for International Clinical Studies Including Therapeutics (ESCISIT). Ann Rheum Dis 2007;66:377-88.

7 Zhang W, Moskowitz RW, Nuki G, et al. OARSI recommendations for the management of hip and knee osteoarthritis, Part II: OARSI evidence-based, expert consensus guidelines. Osteoarth Cartilage 2008;16:137-62.

8 National Institute for Health \& Clinical Excellence. Osteoarthritis: the care and management of osteoarthritis in adults. London: National Institute for Health \& Clinical Excellence, 2008.

9 Croft $\mathrm{P}$, Porcheret M, Peat G. Managing osteoarthritis in primary care: the GP as public health physician and surgical gatekeeper. Br J Gen Pract 2011;61:485-6.

10 Porcheret $\mathrm{M}$, Jordan $\mathrm{K}$, Jinks $\mathrm{C}$, et al. Primary care treatment of knee pain-a survey in older adults. Rheumatology 2007;46:1694-700.

11 McHugh GA, Luker KA, Campbell $M$, et al. A longitudinal study exploring pain control, treatment and service provision for individuals with end-stage lower limb osteoarthritis. Rheumatology 2007:46:631-7.

12 Steel N, Maisey S, Clark A, et al. Quality of clinical primary care and targeted incentive payments: an observational study. Br I Gen Pract 2007:57:449-54.

13 Broadbent J, Maisey $S$, Holland $R$, et al. Recorded quality of primary care for osteoarthritis: an observational study. Br J Gen Pract 2008:58:839.

14 Steel $\mathrm{N}$, Bachmann $\mathrm{M}$, Maisey $\mathrm{S}$, et al. Self reported receipt of care consistent with 32 quality indicators: national population survey of adults aged 50 or more in England. BMJ 2008;337:a957. doi:10.1136/bmj.a957

15 McHugh GA, Campbell M, Luker KA. Quality of care for individuals with osteoarthritis: a longitudinal study. J Eval Clin Pract 2012;18:534-41.

16 Campbell SM, Braspenning J, Hutchinson A, et al. Research methods used in developing and applying quality indicators in primary care. Qual Saf Health Care 2002;11:358-64

17 Lawrence $\mathrm{M}_{1}$, Olesen F. Indicators of Quality in Health Care. Eur J Gen Pract 1997;3:103-8.

18 Hochberg MC. Quality measures in osteoarthritis. Clin Exp Rheumatol 2007. 25(6 Suppl 47):102-6.

19 Strömbeck B, Petersson IF, Vliet Vlieland TPM. Health care quality indicators on the management of rheumatoid arthritis and osteoarthritis: A literature review. Rheumatology 2013;52:382-90.

20 Hunter DJ, Neogi T, Hochberg MC. Quality of osteoarthritis management and the need for reform in the US. Arthritis Care Res 2011;63:31-8.

21 Centre for Reviews and Dissemination. Systematic Reviews: CRD's quidance for undertaking systematic reviews in health care. York: University of York, 2009:292.

22 Agency for Healthcare Research and Quality. http://www.ahrq.gov

23 University of Oxford: Centre for Evidence Based Medicine. Levels of Evidence 2009. http://www.cebm.net/index.aspx?o=1025

24 Campbell SM, Cantrill JA. Consensus methods in prescribing research. J Clin Pharm Ther 2001:26:5-14.

25 Geraedts MAX, Selbmann H-K, Ollenschlaeger G. Critical appraisal of clinical performance measures in Germany. Int I Qual Health Care 2003;15:79.

26 Marshall MN, Shekelle PG, McGlynn EA, et al. Can health care quality indicators be transferred between countries? Qual Saf Health Care 2003;12:8-12.
27 Wollersheim $\mathrm{H}$, Hermens $\mathrm{R}$, Hulscher $\mathrm{M}$, et al. Clinical indicators: development and applications. Neth J Med 2007;65:15-22.

28 Boers $\mathrm{M}$, Brooks $\mathrm{P}$, Strand $\mathrm{CV}$, et al. The OMERACT filter for Outcome Measures in Rheumatology. I Rheumatol 1998;25:198-9.

29 Kerr E, Asch S, Hamilton E, et al. Quality of care for general medical conditions: a review of the literature and quality indicators. Santa Monica, CA: RAND Health, 2000.

30 McGlynn E, Asch S, Adams J, et al. The quality of health care delivered to adults in the United States. New Engl J Med 2003;348:2635.

31 Asch S, McGlynn E, Hogan M, et al. Comparison of Quality of Care for Patients in the Veterans Health Administration and Patients in a National Sample. Ann Intern Med 2004;141:938.

32 MacLean C. Quality indicators for the management of osteoarthritis in vulnerable elders. Ann Intern Med 2001;135:711.

33 Shekelle P, MacLean C, Morton S, et al. Assessing Care of Vulnerable Elders: Methods for Developing Quality Indicators. Ann Intern Med 2001;135(8 Part 2):647.

34 Wenger N, Solomon D, Roth C, et al. The Quality of Medical Care Provided to Vulnerable Community-Dwelling Older Patients. Ann Intern Med 2003;139:740.

35 Chodosh J, Solomon D, Roth C, et al. The quality of medical care provided to vulnerable older patients with chronic pain. J Am Geriatr Soc 2004;52:756.

36 Higashi T, Shekelle P, Solomon D, et al. The Quality of Pharmacologic Care for Vulnerable Older Patients. Ann Intern Med 2004;140:714.

37 Higashi T, Shekelle P, Adams J, et al. Quality of Care Is Associated with Survival in Vulnerable Older Patients. Ann Intern Med 2005:143:274.

38 Ganz D, Chang J, Roth C, et al. Quality of osteoarthritis care for community-dwelling older adults. Arthritis Rheum 2006:55:241.

39 MacLean C, Louie R, Shekelle P, et al. Comparison of administrative data and medical records to measure the quality of medical care provided to vulnerable older patients. Med Care 2006;44:141.

40 Østerås N, Garratt A, Grotle M, et al. Patient-reported quality of care for osteoarthritis: development and testing of the osteoarthritis quality indicator questionnaire. Arthritis Care Res 2013;65:1043-51.

41 Steel N, Melzer D, Shekelle P, et al. Developing quality indicators for older adults: transfer from the USA to the UK is feasible. Qual Saf Health Care 2004; 13:260.

42 Saliba D, Solomon D, Rubenstein L, et al. Quality indicators for the management of medical conditions in nursing home residents. J Am Med Dir Assoc 2005;6:S36.

43 Cadogan M, Schnelle J, Al-Sammarrai N, et al. A standardized quality assessment system to evaluate pain detection and management in the nursing home. J Am Med Dir Assoc 2005;6:1.

44 Zingmond DS, Saliba D, Wilber KH, et al. Measuring the quality of care provided to dually enrolled medicare and medicaid beneficiaries living in nursing homes. Med Care 2009:47:536.

45 Smith K, Soriano T, Boal J. Brief communication: National quality-of-care standards in home-based primary care. Ann Intern Med 2007;146:188.

46 Wenger N, Roth C, Shekelle P, et al. Introduction to the Assessing Care of Vulnerable Elders-3 quality indicator measurement set. J Am Geriatr Soc 2007; 55:S247.

47 ACOVE Investigators. Assessing Care of Vulnerable Elders-3: Quality Indicators. J Am Geriatr Soc 2007;55(Suppl 2):S464.

48 MacLean C, Pencharz J, Saag K. Quality indicators for the care of osteoarthritis in vulnerable elders. J Am Geriatr Soc 2007;55(Suppl 2):S383.

49 Marshall M, Campbell S, Hacker J, et al. eds. Quality indicators for general practice. London: RSM Press, 2002.

50 Kirk S, Campbell S, Kennell-Webb S, et al. Assessing the quality of care of multiple conditions in general practice: practical and methodological problems. Qual Saf Health Care 2003;12:421.

51 MacLean C, Saag KS, Solomon D, et al. Measuring quality in arthritis care: methods for developing the Arthritis Foundation's quality indicator set. Arthritis Rheum 2004;51:193.

52 Pencharz J, MacLean C. Measuring quality in arthritis care: the Arthritis Foundation's Quality Indicator set for osteoarthritis. Arthritis Rheum 2004;51:538.

53 Li L, Sayre E, Kopec J, et al. Quality of nonpharmacological care in the community for people with knee and hip osteoarthritis. J Rheumatol 2011:38:2230.

54 American Academy of Orthopaedic Surgeons, Physician Consortium for Performance Improvement. Osteoarthritis: Physician Performance Measurement Set. 2006. http:/l www.aaos.org/research/committee/evidence/PCPI_Measures_Osteoarthritis.pdf

55 EUMUSC.net. Health care quality indicators for OA. 2012. http://www.eumusc.net/ workpackages_wp6.cfm

56 Higgins JPT, Green S. eds. Cochrane Handbook for Systematic Reviews of Interventions Version 5.1.0 [updated March 2011]. The Cochrane Collaboration, 2011.

57 House of Commons Committee of Public Accounts. Department of Health: Prescribing costs in primary care. London: The Stationery Office Limited, 2007.

58 NHS Employers. Quality \& Outcomes Framework. 2013. http://www.nhsemployers. org/PayAndContracts/GeneralMedicalServicesContract/QOF/Pages/QualityOutcomes Framework.aspx 